\title{
Dietary Factors Affecting the Prevalence and Impact of Periodontal Disease
}

\section{Simona Santonocito \\ Alessandro Polizzi \\ Giuseppe Palazzo \\ Francesco Indelicato \\ Gaetano Isola}

Department of General Surgery and Surgical-Medical Specialties, School of Dentistry, University of Catania, Catania, Italy
Correspondence: Gaetano Isola

Unit of Periodontology, Department of General Surgery and Surgical-Medical

Specialties, School of Dentistry, University of Catania, Via S. Sofia 78, Catania, 95I23, Italy

Tel/Fax +390953782453

Email gaetano.isola@unict.it
Abstract: In the last few decades, growing evidence have shown a possible impact of diet and nutrients on oral health. This review aims to describe, in the light of current knowledge, the role of diet, nutrients, and micronutrients in periodontal health and periodontal diseases. A variety of macronutrients and micronutrients could have an impact on periodontal health. The balanced intake of unprocessed complex carbohydrates, vegetable proteins, omega-3 fatty acids, minerals, and vitamins positively affects periodontal inflammation. On the other way, refined carbohydrates, non-vegetable proteins, proinflammatory saturated fatty acids and an unbalanced supply of vitamins and minerals may increase periodontal inflammation. This review will discuss the current evidence that shows how a healthy and balanced diet has anti-inflammatory and protective effects on periodontal health. Therefore, it appears that adopting a correct lifestyle and diet should be encouraged in patients with oral and periodontal disease.

Keywords: periodontitis, nutrition, diet, macronutrients, micronutrients, oral health

\section{Introduction}

The oral cavity, due to the anatomical position and function, is not sterile but it is colonized in the several surfaces (tooth, gingiva, tongue and mucous membranes) by microorganisms organized in biofilms which is a self-produced matrix of hydrated extracellular polymeric substances and which differs among the surfaces. $^{1-4}$ Periodontitis is an inflammatory disease of the tooth's supporting tissues caused by specific microorganisms resulting in progressive destruction of the periodontal ligament and alveolar bone. ${ }^{5}$ It affects $10-15 \%$ of the world's population, ${ }^{6}$ it's a major cause of tooth loss in adults ${ }^{7}$ and has been associated with systemic factors such as diabetes ${ }^{8}$ and cardiovascular disease. ${ }^{9,10}$ The etiology of periodontitis primary involves the plaque biofilm associated with poor oral hygiene. ${ }^{11}$ However, an abnormal inflammatory response in predisposed patients determines most tissue destruction. ${ }^{12}$ Therefore, periodontitis results from an unbalanced immune reaction of the host against an organized dysbiotic biofilm. Periodontopathogenic bacteria release metabolites and enzymes that aggravate tissue damage and, at the same time, leukocytes and fibroblasts produce various inflammatory mediators, including cytokines, prostaglandins, reactive oxidative species (ROS), proteolytic enzymes and metalloproteinases. ${ }^{13-16}$ The inflammatory infiltrate from periodontal tissues induces tissue and alveolar bone destruction. ${ }^{17}$

A variety of nutrients have a major impact on periodontal health. ${ }^{18-20}$ Some evidence suggests that both macronutrients (nutrients required in large quantities 
such as carbohydrates, fats and proteins) and micronutrients (required in small amounts such as vitamins and minerals) could modulate proinflammatory and antiinflammatory cascades, influencing, in general, the host immune response ${ }^{21,22}$ (Figure 1).

Therefore, this review aims to describe the relationship between nutrients and periodontal disease in light of current knowledge.

\section{Carbohydrates}

Carbohydrates are a significant source of energy and they also aid in fat metabolism. ${ }^{20}$ Low-glycemic, unprocessed, complex carbohydrates, usually rich in fibers (like fruits, whole grain, vegetables, legumes) are generally healthy, whereas high-glycemic, processed, fermentable carbohydrates, usually poor in fibers (like refined sugar, white wheat flour, sugary drinks) can be major causes of chronic inflammation. $^{21,23,24}$ In fact, high caloric carbohydrate consumption causes systemic proinflammatory effects. $^{25}$

Nutrition, and in particular fermentable carbohydrates, can influence the oral biofilm composition and may induce the onset of oral diseases such as dental caries and periodontitis. $^{26,27}$ However, recent studies also showed an influence of sugar on gingival inflammation which might be etiologically related to both local and systemic effects like elevated blood sugar. ${ }^{23,28}$ Instead it was observed that a diet that includes the consumption of uncooked vegetables can have periodontal health benefits. Chewing raw vegetables is known to promote oral selfdetoxification, resulting in less plaque build-up on the tooth surface, reducing periodontal inflammation and the development of caries and promoting periodontal and dental health. ${ }^{29}$

In a recent study, it was observed that individuals following a vegetarian diet had a lower incidence of gum inflammation and better overall oral hygiene. ${ }^{30}$ It was also observed that vegetarians had better overall oral health, showing good self-care and prevention, which could be partly attributed to their focus on maintaining a healthy lifestyle. However, in two studies conducted by Laffranchi et $\mathrm{al}^{31}$ and Smits and al. ${ }^{32}$ respectively, it was found that subjects on a vegetarian diet had a higher prevalence of white spot lesions on the teeth and dental

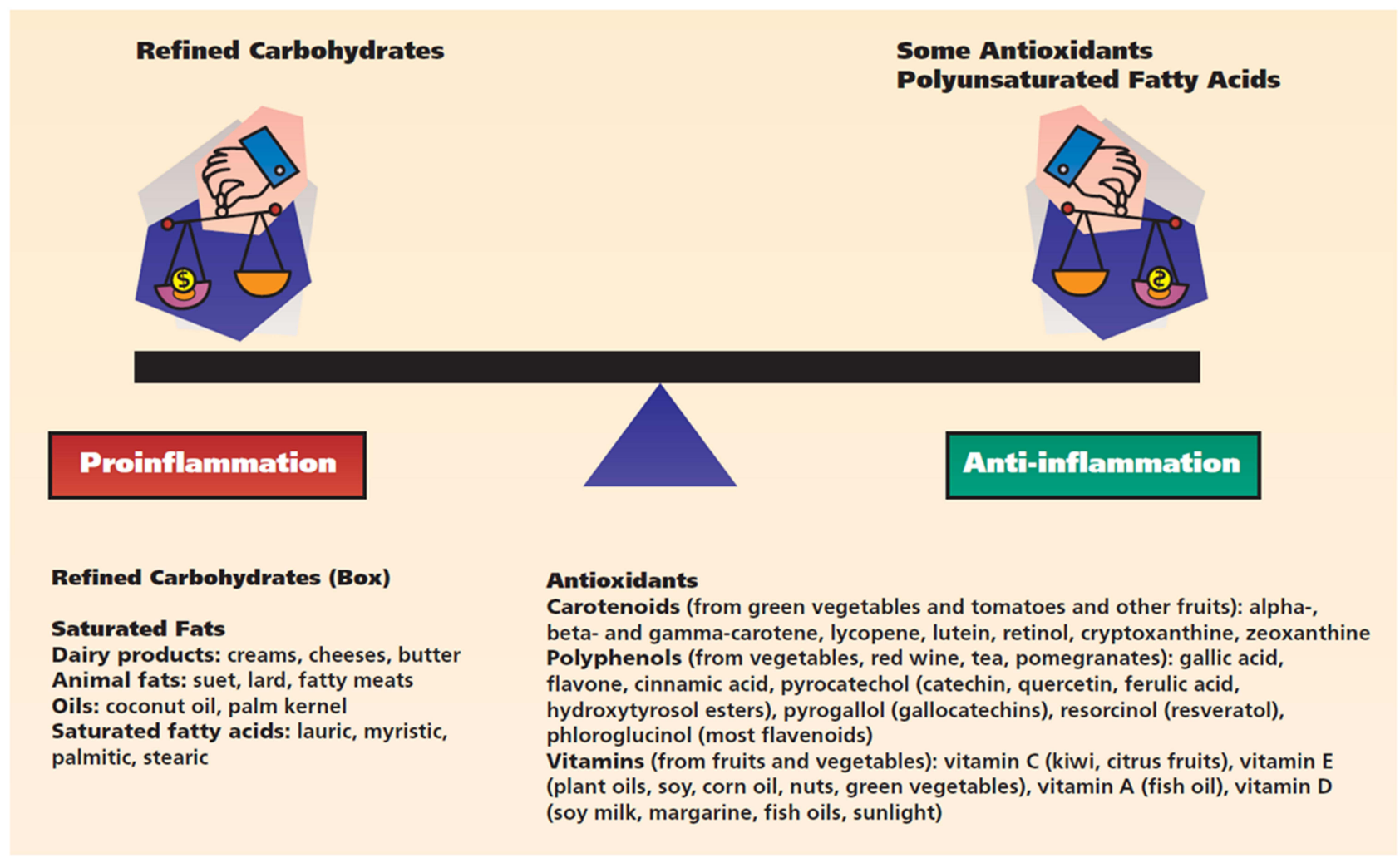

Figure I Macronutrients and micronutrients mechanistically associated with the regulation of inflammatory processes. Reprinted from The Journal of the American Dental Association, I40(2), Chapple IL, Potential mechanisms underpinning the nutritional modulation of periodontal inflammation, I78-184, Copyright (2009), with permission from Elsevier. $^{22}$ 
erosions than controls, due to a lower salivary $\mathrm{pH}$ that was more acidic than controls.

Furthermore, systemic diseases may influence the tissue response to the microbial biofilm in patients affected by periodontal disease. For example some studies showed that the development of periodontal disease in subject suffering from coronary heart disease is faster and more aggressive than in healthy subjects ${ }^{33}$ and that following a gluten-free diet could be important to control the gingival bleeding levels in patients affected by coeliac disease. ${ }^{34}$ The correlation between diabetes and periodontitis was well established years ago. ${ }^{35}$ However, recent evidences suggest that even high-glycaemic food consumption alone could increase gingival and periodontal inflammation and gingival bleeding, whereas a diet rich in complex carbohydrates without increasing total energy intake may reduce gingivitis and periodontitis risk. ${ }^{28,36-40}$ Furthermore, obesity, a marker of excessive fermentable carbohydrate intake, has been demonstrate to determine an increased risk of periodontitis. ${ }^{41,42}$ But physical activity, which reduces blood glucose levels, is associated with a reduced risk of periodontitis in adults. ${ }^{43}$ A recent workshop established that processed carbohydrates are a risk factor for both caries and periodontitis. ${ }^{44}$

\section{Proteins}

The role of proteins in systemic inflammation has not yet been well defined, although most evidence attributes a neutral role to them. ${ }^{25}$ In recent years, it has been noted that the biological value of proteins and their role in genetic inflammation depends on their origin. Animal proteins are thought to increase insulin-like growth factor 1, which has been found to play an important role in carcinogenesis. ${ }^{45,46}$ In contrast, vegetable proteins show a reduction in the risk of cardiovascular disease, type 2 diabetes mellitus and kidney disease. ${ }^{47}$ According to this evidence, several European dietary guidelines recommend reducing meat consumption, especially processed meat, to less than 500 g per week.

Few studies have investigated the role of protein in periodontal disease. In a cross-sectional clinical study by Staufenbiel et al the periodontal status of 100 vegetarians was compared to 100 non-vegetarians. The results showed that the vegetarian group had significantly less pocket depth, less bleeding on probing and better oral hygiene than the nonvegetarian patients. Therefore, the vegetarian diet seems to have a positive influence on periodontal health. The authors pointed out that vegetarian patients had a higher level of education and a healthier lifestyle than non-vegetarians. ${ }^{48}$

\section{Lipids}

Lipids are an important source of energy and structural and metabolic components (such as cell membranes and hormones). Several studies have shown that inflammation is mainly promoted by unhealthy saturated fats (Figure 2), such as trans fats and omega- 6 fatty acids. ${ }^{25}$ They are most frequently found in industrial meat, dairy products and eggs, vegetable oils (safflower oil, sunflower oil, grape seed oil and margarine). Trans fats, on the other hand, are mostly the result of the overheating of fats and are therefore typical of

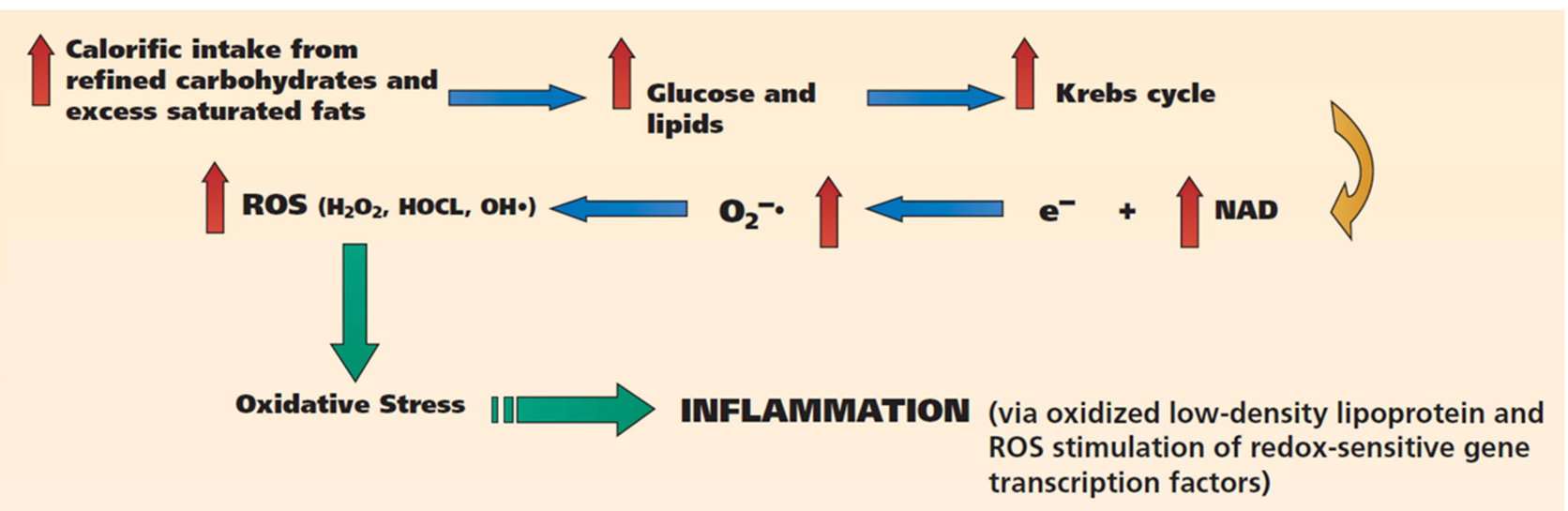

Figure 2 Postprandial dysmetabolism: diets rich in refined carbohydrates and saturated fats stimulate inflammation via the generation of excess ROS and oxidative stress. Reprinted from The Journal of the American Dental Association, I40(2), Chapple IL, Potential mechanisms underpinning the nutritional modulation of periodontal inflammation, 178-184, Copyright (2009), with permission from Elsevier. ${ }^{22}$

Abbreviations: $\mathrm{H} 2 \mathrm{O} 2$, hydrogen peroxide; $\mathrm{HOCl}$, hypochlorous acid; e-, electron; $\mathrm{NAD}$, nicotinamide adenine dinucleotide; O2-•, superoxide; OH•, hydroxyl radical; ROS, reactive oxygen species. 
particular forms of food cooking, such as frying, baking or roasting. ${ }^{49}$

Iwasaki et al conducted a longitudinal study of 264 Japanese participants and showed that there was a statistically positive association between saturated fatty acids and the occurrence of periodontal lesions. ${ }^{50}$ In contrast, omega-3 fatty acids have been intensively studied in recent years because they are associated with less systemic inflammation. $^{25}$ In fact, they have shown antiinflammatory effects, which have completely overturned the historical view that the elimination of inflammation is an exclusively passive process based on the elimination of the triggering factor. Instead, it is now believed that inflammation is actively resolved by so-called specialised pro-resolution mediators, which are metabolites of omega3 fatty acids. This has been referred to as the resoleomics theory, first described in the study by Serhan et al. ${ }^{51}$ Taking aspirin in combination with omega-3 fatty acids may lead to the production of more potent resolvins and protectors, increasing the anti-inflammatory effects. ${ }^{52,53}$ Growing evidence supports the theory that Omega-3 fatty acids also lead to the resolution of inflammatory processes in periodontal tissues, both in vivo and in vitro. ${ }^{54}$ It is now known that an imbalance between omega- 6 and omega- 3 fatty acids promotes inflammation. This is supported by several evidences indicating that a diet based almost exclusively on refined carbohydrates and saturated fatty acids has altered the Omega- 6 to Omega- 3 ratio from 1:1 in a hunter-gatherer diet to $15: 1$ in a Western diet. This also leads to increased blood levels of several cytokines. ${ }^{55}$ In a study by Baumgartner ${ }^{36}$ et al 10 volunteers lived for 4 weeks under "stone age" conditions, in the absence of oral hygiene and a highly processed diet. It was observed that periodontal inflammation (measured as bleeding on probing) decreased from 34.8 to $12.6 \%$, despite the participants showing significant plaque accumulation. ${ }^{55}$ These results lead to the conclusion that the experimental gingivitis protocol is not applicable in the absence of simple processed carbohydrates, like sugar and processed cereals. The study carried out by Baumgartner et al represents the first in a series of studies confirming that a lifestyle that includes a lot of refined carbohydrates and a high ratio of Omega- 6 to Omega-3 fatty acids promotes inflammatory processes. Their nutritional intake gives the relationship between omega-3 and omega- 6 fatty acids in the tissues. In a study conducted at the University of Freiburg, Germany, a group of patients switched from a Western diet (rich in processed carbohydrates and proinflammatory saturated fatty acids) to a diet low in processed carbohydrates but rich in omega- 3 fatty acids, vitamin $\mathrm{C}$, vitamin $\mathrm{D}$ and fibre. The results showed that, although plaque values did not change, gingival and periodontal inflammation in the patients tested decreased by about half. ${ }^{37}$ Omega-3 fatty acids are found in marine algae, fatty sea fish (salmon and oily fish) and various seeds and nuts and their corresponding oils (linseed, walnuts, chia seeds etc.). Several clinical studies in the field of periodontology have demonstrated a reduction in periodontal inflammation and/or pocket depth through omega-3 fatty acid supplementation, whether taken in the form of fish oil supplements or naturally caught fatty fish or taken from plant sources. ${ }^{56,57} \mathrm{~A}$ recent literature review indicated that omega-3 fatty acids, as an adjunct to periodontal therapy, showed significant benefits in reducing pocket depth and increasing attachment. ${ }^{53}$

\section{Micronutrients}

The term 'micronutrients' includes vitamins, minerals and trace elements. They are required by the body in quantities of less than $100 \mathrm{mg} /$ day and are believed to influence periodontal disease ${ }^{58}$ Vitamins $\mathrm{A}, \mathrm{D}, \mathrm{E}$ and $\mathrm{K}$ have the characteristic of dissolving in fat, whereas vitamins $\mathrm{B}$ complex and vitamin $\mathrm{C}$ are hydrophilic and dissolve in water. Micronutrient deficiencies may be caused by medication (antacids, antibiotics, antihypertensives, chelation agents, corticosteroids, diuretics, laxatives, NSAIDs), malabsorption or diarrhoea, lifestyle factors (diet, malnutrition, chronic alcohol or nicotine abuse and consumption of fast food or processed foods), systemic disorders (diabetes mellitus, thyroid and parathyroid disorders), and increased requirements (pregnancy, breastfeeding, growth, physical/mental stress). Absorption and utilisation of nutrients are influenced by both physiological and nutritional factors that may vary throughout life. On the other hand, bioavailability depends on the chemical form and often also on the co-presence of other micronutrients, for example, vitamin D and calcium. ${ }^{59}$ Positive effects on periodontal health have been found in the different vitamins ${ }^{60,61}$ (Figure 3).

Russell et al carried out a nutritional survey of more than 21,000 people in Alaska, Ethiopia, Ecuador, South Vietnam, Chile, Colombia, Thailand and Lebanon, showing that populations with high scores for periodontal disease tended to be vitamin A deficient. ${ }^{62}$ In a more recent study, Dodington et al showed that a higher dietary intake of beta-carotene $(\geq 7.07 \mathrm{mg} / \mathrm{d})$ was associated with 


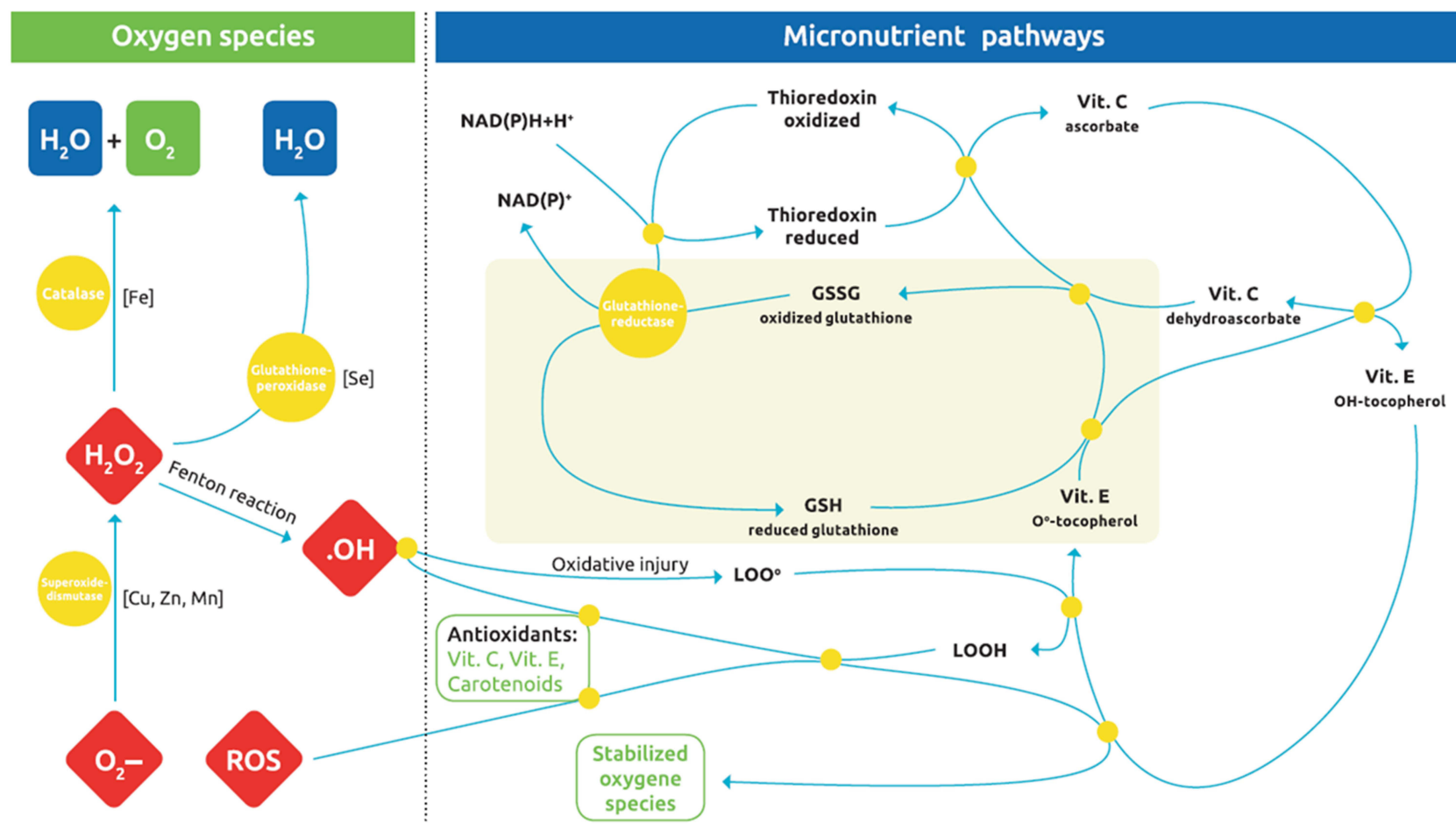

Figure 3 The complex oxidation-reduction pathways through which oxidative stress is abrogated by various antioxidant micronutrients, through redox-cycling reactions. Glutathione is ultimately the chain-breaking antioxidant species that forms the nonradical GSSG (oxidized glutathione) and is also a master regulator of the cellular redox state and inflammatory gene transcription factors. Reproduced from Dommisch H, Kuzmanova D, Jönsson D, et al. Effect of micronutrient malnutrition on periodontal disease and periodontal therapy. Periodontol. (C) 2018 John Wiley \& Sons A/S. Published by John Wiley \& Sons Ltd. ${ }^{63}$

Abbreviations: $\mathrm{Cu}$, copper; Fe, iron; H2O2, hydrogen peroxide; LOO, peroxyl radical; LOOH, lipid hydroperoxide; Mn, manganese; ROS, reactive oxygen species; Se, selenium; Zn, zinc.

a significantly lower percentage of sites with probing depths $>3 \mathrm{~mm}$ at follow-up after non-surgical periodontal treatment. It was also associated with a greater reduction in pocket depth in adult non-smokers than in adult smokers with chronic periodontitis. ${ }^{18}$ The role of vitamin A in periodontal therapy has not yet been fully investigated. This may be attributed to the epeatic toxicity induced by vitamin A excess. For this very reason, no studies of monovitamin supplementation have been carried out. ${ }^{63}$

A study by Zong et al found that individuals with low serum levels of vitamin B12 had an increased risk of developing periodontal lesions. ${ }^{60}$ This highlights the importance of vitamin B12 supplementation for vegans, and sometimes even vegetarians. ${ }^{61}$ Neiva et al showed that taking a cocktail of B vitamins (vitamin B12, folate, thiamine $\mathrm{HCl}$, riboflavin, niacinamide, d-calcium pantothenate, pyridoxine $\mathrm{HCl}$ and D-biotin) has positive effects on periodontal wound healing in patients with chronic periodontitis who have undergone periodontal surgery. Indeed, supplementation with B-complex vitamins improved clinical attachment level compared with placebo-treated patients. $^{64}$ In a double-blind, placebocontrolled study, the effects of a mouthwash containing folate was investigated in patients with gingivitis and periodontitis. It was found that patients who used the mouthwash for 4 weeks showed a reduction in bleeding on probing and less gingival redness than patients who received a placebo mouthwash during the same period. ${ }^{65}$

Cross-sectional studies have shown lower serum vitamin $\mathrm{C}$ values and lower vitamin $\mathrm{C}$ intake in patients with periodontal disease compared to controls. ${ }^{66,67}$ Two clinical studies indicated that increased consumption of fruits containing vitamin $\mathrm{C}$ (such as grapefruits, peppers, kiwis, etc.) could reduce gingival and periodontal inflammation. ${ }^{37,68}$ In contrast, supplementation with $2 \mathrm{~g}$ of synthetic vitamin $\mathrm{C}$ in addition to surgical periodontal therapy showed no benefit, after 1 month in a placebo-controlled study. ${ }^{69}$ Individuals with vitamin $\mathrm{C}$ deficiency were found to have a greater loss of attachment than individuals with normal serum levels. ${ }^{70}$ Independent of oral hygiene, 
vitamin $\mathrm{C}$ depletion causes gingival bleeding. ${ }^{71}$ Indeed, it is known that during inflammation, histamine is responsible for regulating regional blood flow, resulting in redness, swelling and oedema. Vitamin $\mathrm{C}$ has antihistamine properties, so sufficient vitamin $\mathrm{C}$ may contribute to healthy gingival homeostasis, despite the presence of bacteria. ${ }^{72}$

The role of vitamin $\mathrm{D}$ in periodontal disease has been studied extensively in recent years. It is known that vitamin D plays an essential role in calcium absorption and bone metabolism. It also plays an active role in the regulation of the immune system and therefore has significant anti-inflammatory properties. ${ }^{73}$ In a case-control study, Laky et al showed that patients with periodontal disease had a higher vitamin D deficiency $(<50 \mathrm{nmol} / \mathrm{L})$ than healthy participants. ${ }^{74}$ In a study of Dietrich et al, the authors found less alveolar bone loss in both men and women over 50 who had the highest quartile of serum 25hydroxy vitamin $\mathrm{D}$ than those with the lowest quartile, with a greater protective effect in men. To determine the anti-inflammatory effects of serum vitamin D on gingival inflammation, signs of periodontal inflammation were compared in the highest versus the lowest quartile of 25hydroxy vitamin D. Interestingly, subjects in the high quartile of vitamin D were $20 \%$ less likely to show bleeding on examination. ${ }^{75}$ Vitamin $\mathrm{D}$ values were found to be inversely correlated with clinical attachment loss and tooth loss in three cross-sectional studies. ${ }^{76}$ However, there are also conflicting study results and a lack of interventional randomised controlled trials. ${ }^{58}$

Iwasaki et al conducted a prospective study based on 264 Niigata citizens, 75 years old, with a follow-up period of 2 years. The results showed that a higher intake of vitamin E was inversely associated with the number of teeth with periodontal disease progression. In addition, a high intake of fruit and vegetables was protective against periodontal disease. ${ }^{77}$ Table 1 resumes major vitamins dietary sources and their effects on periodontal tissues.

Table I Major Vitamins, Their Dietary Sources, Daily Requirements, Deficiency Diseases, and Reported Importance in Periodontal Health

\begin{tabular}{|c|c|c|c|c|}
\hline Nutrient & Dietary Sources(s) & Importance in Periodontal Health & $\begin{array}{l}\text { Reported } \\
\text { Improvement in } \\
\text { PD and CAL } \\
\text { (Mean } \mathrm{mm}, \mathrm{SD} \text { ) }\end{array}$ & References \\
\hline Vitamin A & $\begin{array}{l}\text { Cod liver oil, carrots, capsicum, liver, sweet } \\
\text { potato, broccoli, leafy vegetables }\end{array}$ & $\begin{array}{l}\text { Not clear. Research indicates insignificant } \\
\text { improvement in periodontal health upon } \\
\text { supplementation. }\end{array}$ & $\begin{array}{l}\text { PD: } 0.52 \pm 0.03 \\
\text { CAL: n.d. }\end{array}$ & {$[14,66]$} \\
\hline B-vitamins & $\begin{array}{l}\text { BI-Liver, oats, pork, potatoes, eggs B2- } \\
\text { Bananas, dairy, green beans B3-Eggs, fish, meat, } \\
\text { mushrooms, nuts B5-Avocados, meat, broccoli } \\
\text { B7-Raw egg, liver, leafy vegetables, peanuts B9 } \\
\text {-Cereals, leafy vegetables BI2-Animal } \\
\text { products }\end{array}$ & $\begin{array}{l}\text { Supplementation may accelerate post- } \\
\text { surgical healing. }\end{array}$ & PD: $1.57 \pm 0.34$ & [53] \\
\hline Vitamin C & Citrus fruits, vegetables, liver & $\begin{array}{l}\text { Gingival bleeding and Inflammation are } \\
\text { hallmarks of scurvy. Supplementation may } \\
\text { improve outcomes of periodontal } \\
\text { therapy. }\end{array}$ & $\begin{array}{l}\text { PD: } 0.58 \pm 0.14 \\
\text { CAL: n.d. }\end{array}$ & [58] \\
\hline Vitamin D & Fish eggs, mushrooms, liver, milk & $\begin{array}{l}\text { Deficiency may lead to delayed post- } \\
\text { surgical healing. Local application may } \\
\text { accelerate post-surgical healing/ } \\
\text { osseointegration }\end{array}$ & $\begin{array}{l}\text { PD: I.35 (SD n.d.) } \\
\text { CAL: I.4 (SD n.d.) }\end{array}$ & {$[53,67-69]$} \\
\hline Vitamin E & Green vegetables, egg yolk & $\begin{array}{l}\text { Deficiency may lead to gingival bleeding. } \\
\text { No known effects on periodontal therapy } \\
\text { if supplementation used as an adjunct. }\end{array}$ & n.d. & {$[14,70-72]$} \\
\hline
\end{tabular}

Note: Adapted from Najeeb S, Zafar MS, Khurshid Z, Zohaib S, Almas K. The Role of Nutrition in Periodontal Health: An Update. Nutrients. 20I6;30;8(9):530. ${ }^{81}$ Abbreviations: PD, pocket depth; CAL, clinical attachment level; n.d., not determined; SD, standard deviations. 
Minerals and trace elements can also influence periodontal health. In two systematic reviews, the roles of calcium and magnesium in periodontal disease were investigated. $^{78,79}$ Magnesium deficiency was correlated with a higher incidence of periodontal disease in adults $^{80}$ and that calcium intake was inversely related to periodontal disease in young Japanese women. ${ }^{81}$ Nishida et al observed that low dietary calcium intake results in more severe periodontal disease. ${ }^{82} \mathrm{Al}$-Zahrani et al conducted a nutritional survey to identify which dairy products may positively affect periodontal disease. It was noted that the intake of products obtained from lactose fermentation, such as yoghurt, had a significant effect on periodontal disease. No significant associations were found with the intake of milk, cheese and other dairy products. ${ }^{83}$ The authors believed that the beneficial effects of yoghurt on periodontal disease could be attributed to the protective role of probiotic bacteria, which suppress the growth of periodontal pathogens in the oral cavity and stimulate the immune system. ${ }^{84}$ Meisel et al studied the association between magnesium and periodontal health in 4290 subjects and hypomagnesemia was found in $35 \%$ of all participants. The authors concluded that there is a significant association between periodontal health and serum magnesium levels. They stress that nutritional supplementation of magnesium could improve periodontal health and prevent or delay tooth loss, especially in middle-aged people. ${ }^{80}$ Table 2 resumes major minerals dietary sources and their effects in periodontal tissues.

In a randomised placebo-controlled study, Chapple et al reported a positive effect of vegetable/fruit/berry capsules on periodontal clinical outcomes after non-surgical periodontal therapy. ${ }^{85}$ Another study conducted in Sweden found that daily intake of $500 \mathrm{~g}$ of cranberries can significantly reduce gingival inflammation in patients with gingivitis. ${ }^{86}$

\section{Oral Hygiene}

The accumulation of dental plaque and tartar, associated with poor oral hygiene, is one of the risk factors in the development of periodontal disease. ${ }^{87}$ This accumulation predictably causes gingival inflammation, which if persistent can lead to the breakdown of the periodontal attachment and thus to periodontal disease. ${ }^{88}$ In several studies it has been observed that there is a dose-response relationship between oral hygiene and periodontitis. Thus, average and poor oral hygiene significantly increase the risk of having periodontitis by two and five times, respectively, compared to good $\mathrm{OH}$. In contrast, regular tooth brushing and visits to the dentist could reduce periodontitis by $34 \%$ and $32 \%$ respectively. ${ }^{87}$ In most

Table 2 Major Minerals, Their Dietary Sources, Daily Requirements, Deficiency Diseases, and Reported Importance in Periodontal Health

\begin{tabular}{|c|c|c|c|c|}
\hline Nutrient & Dietary Sources(s) & Importance in Periodontal Health & $\begin{array}{l}\text { Reported } \\
\text { Improvement in PD } \\
\text { and CAL (Mean } \mathrm{mm} \text {, } \\
\text { SD) }\end{array}$ & References \\
\hline Calcium & $\begin{array}{l}\text { Milk products, eggs, } \\
\text { canned bony fish, leafy } \\
\text { vegetables, nuts, seeds }\end{array}$ & $\begin{array}{l}\text { Required for formation of teeth and bones. } \\
\text { Supplementation improves outcomes of non-surgical } \\
\text { periodontal therapy. Local application enhances } \\
\text { osseointegration. }\end{array}$ & n.d. & {$[73,74]$} \\
\hline Magnesium & $\begin{array}{l}\text { Cocoa, soybeans, nuts, } \\
\text { spinach, marine } \\
\text { vegetables, tomatoes }\end{array}$ & $\begin{array}{l}\text { Required for cell metabolism and bone formation. } \\
\text { Supplementation may improve outcomes of non-surgical } \\
\text { periodontal therapy. }\end{array}$ & n.d. & {$[75]$} \\
\hline Iron & $\begin{array}{l}\text { Red meat, tuna, dry } \\
\text { beans, spinach }\end{array}$ & Possible anti-oxidant effect on periodontium. & n.d. & [76] \\
\hline Zinc & $\begin{array}{l}\text { Protein-rich foods, } \\
\text { spinach, grains }\end{array}$ & $\begin{array}{l}\text { Possible anti-oxidant effect on periodontium. Reduces } \\
\text { severity of diabetes-induced periodontitis }\end{array}$ & n.d. & [77] \\
\hline Fluoride & $\begin{array}{l}\text { Grape fruits, cocoa, tea, } \\
\text { dried fruits and nuts, } \\
\text { fluoridated water }\end{array}$ & $\begin{array}{l}\text { Supplementation and topical application prevents dental } \\
\text { caries. }\end{array}$ & n.d. & [78] \\
\hline
\end{tabular}

Note: Adapted from Najeeb S, Zafar MS, Khurshid Z, Zohaib S, Almas K. The Role of Nutrition in Periodontal Health: An Update. Nutrients. 20I6;30;8(9):530. ${ }^{81}$ Abbreviations: PD, Pocket depth; CAL, clinical attachment level; n.d., not determined. 
cases, plaque accumulation could be due to incorrect brushing techniques, failure to clean interdentally and irregular dental visits. In another study, regular brushing was observed to have protective effects on oral health, with infrequent tooth brushing significantly increasing the risk of periodontitis. ${ }^{89}$

\section{Conclusions}

Fruits and vegetables are great sources of micronutrients and antioxidants, which have a positive and protective effect on periodontal health. Evidence shows that a healthy and balanced diet has anti-inflammatory and protective effects on periodontal health. Therefore, the adoption of a correct lifestyle and diet should be encouraged in patients with periodontal disease.

\section{Author Contributions}

All authors made substantial contributions to conception and design, acquisition of data, or analysis and interpretation of data; took part in drafting the article or revising it critically for important intellectual content; agreed to submit to the current journal; gave final approval of the version to be published; and agree to be accountable for all aspects of the work.

\section{Disclosure}

The authors declares that they have no conflicts of interest in the present manuscript.

\section{References}

1. Burchard T, Karygianni L, Hellwig E, et al. Microbial composition of oral biofilms after Visible Light and Water-Filtered Infrared a Radiation (VIS+wIRA) in combination with Indocyanine Green (ICG) as photosensitizer. Antibiotics (Basel). 2020;9(9). doi:10.3390/ antibiotics 9090532 .

2. Bernardi S, Karygianni L, Filippi A, et al. Combining culture and culture-independent methods reveals new microbial composition of halitosis patients' tongue biofilm. Microbiologyopen. 2020;9(2):e958. doi: $10.1002 / \mathrm{mbo3} .958$

3. Bernardi S, Continenza MA, Al-Ahmad A, et al. Streptococcus spp. and Fusobacterium nucleatum in tongue dorsum biofilm from halitosis patients: a fluorescence in situ hybridization (FISH) and confocal laser scanning microscopy (CLSM) study. New Microbiol. 2019;42 (2):108-113.

4. Flemming HC, Wingender J. The biofilm matrix. Nat Rev Microbiol. 2010;8(9):623-633. doi:10.1038/nrmicro2415

5. Tonetti MS, Greenwell H, Kornman KS. Staging and grading of periodontitis: framework and proposal of a new classification and case definition. J Periodontol. 2018;89(Suppl 1):S159-S172. doi:10.1002/JPER.18-0006

6. Petersen PE, Ogawa H. Strengthening the prevention of periodontal disease: the WHO approach. J Periodontol. 2005;76(12):2187-2193. doi:10.1902/jop.2005.76.12.2187

7. Papapanou PN. Epidemiology of periodontal diseases: an update. J Int Acad Periodontol. 1999;1(4):110-116.
8. Preshaw PM, Alba AL, Herrera D, et al. Periodontitis and diabetes: a two-way relationship. Diabetologia. 2012;55(1):21-31. doi:10.1007/ s00125-011-2342-y

9. Isola G, Polizzi A, Alibrandi A, Williams RC, Leonardi R. Independent impact of periodontitis and cardiovascular disease on elevated soluble urokinase-type plasminogen activator receptor (suPAR) levels. J Periodontol. 2020.

10. Isola G, Polizzi A, Alibrandi A, et al. Analysis of endothelin-1 concentrations in individuals with periodontitis. Sci Rep. 2020;10 (1):1652. doi:10.1038/s41598-020-58585-4

11. Axelsson P, Albandar JM, Rams TE. Prevention and control of periodontal diseases in developing and industrialized nations. Periodontol 2000. 2002;29:235-246. doi:10.1034/j.16000757.2002.290112.x

12. Page RC, Kornman KS. The pathogenesis of human periodontitis: an introduction. Periodontol 2000. 1997;14:9-11. doi:10.1111/j.16000757.1997.tb00189.x

13. Graves DT, Jiang Y, Valente AJ. The expression of monocyte chemoattractant protein-1 and other chemokines by osteoblasts. Front Biosci. 1999;4:D571-80. doi:10.2741/Graves

14. Yan K, Lin Q, Tang K, et al. Substance P participates in periodontitis by upregulating HIF-1alpha and RANKL/OPG ratio. BMC Oral Health. 2020;20(1):27. doi:10.1186/s12903-020-1017-9

15. Ye D, Gajendra S, Lawyer G, et al. Inflammatory biomarkers and growth factors in saliva and gingival crevicular fluid of e-cigarette users, cigarette smokers, and dual smokers: a pilot study. J Periodontol. 2020;91(10):1274-1283. doi:10.1002/JPER.19-0457

16. Chapple IL. Reactive oxygen species and antioxidants in inflammatory diseases. J Clin Periodontol. 1997;24(5):287-296. doi:10.1111/ j.1600-051X.1997.tb00760.x

17. Uchida M, Shima M, Shimoaka T, et al. Regulation of matrix metalloproteinases (MMPs) and tissue inhibitors of metalloproteinases (TIMPs) by bone resorptive factors in osteoblastic cells. $J$ Cell Physiol. 2000;185(2):207-214. doi:10.1002/1097-4652(200011) 185:2<207::AID-JCP5>3.0.CO;2-J

18. Ritchie CS, Kinane DF. Nutrition, inflammation, and periodontal disease. Nutrition. 2003;19(5):475-476. doi:10.1016/S0899-9007(02)01043-2

19. Schifferle RE. Nutrition and periodontal disease. Dent Clin. 2005;49 (3):595-610. doi:10.1016/j.cden.2005.03.008

20. O'Keefe JH, Gheewala NM, O'Keefe JO. Dietary strategies for improving post-prandial glucose, lipids, inflammation, and cardiovascular health. J Am Coll Cardiol. 2008;51(3):249-255. doi:10.1016/j. jacc.2007.10.016

21. Chapple IL. Potential mechanisms underpinning the nutritional modulation of periodontal inflammation. J Am Dent Assoc. 2009;140 (2):178-184. doi:10.14219/jada.archive.2009.0131

22. Woelber JP, Tennert C. Chapter 13: diet and periodontal diseases. Monogr Oral Sci. 2020;28:125-133.

23. Mitrou PN, Kipnis V, Thiébaut AC, et al. Mediterranean dietary pattern and prediction of all-cause mortality in a US population: results from the NIH-AARP Diet and Health Study. Arch Intern Med. 2007;167(22):2461-2468. doi:10.1001/archinte.167.22.2461

24. van Woudenbergh GJ, Theofylaktopoulou D, Kuijsten A, et al. Adapted dietary inflammatory index and its association with a summary score for low-grade inflammation and markers of glucose metabolism: the Cohort study on Diabetes and Atherosclerosis Maastricht (CODAM) and the Hoorn study. Am J Clin Nutr. 2013;98(6):1533-1542. doi:10.3945/ajcn.112.056333

25. Vach K, Al-Ahmad A, Anderson A, et al. Analysing the relationship between nutrition and the microbial composition of the oral biofilm-insights from the analysis of individual variability. Antibiotics (Basel). 2020;9(8). doi:10.3390/antibiotics9080479.

26. Anderson AC, Rothballer M, Altenburger MJ, et al. In-vivo shift of the microbiota in oral biofilm in response to frequent sucrose consumption. Sci Rep. 2018;8(1):14202. doi:10.1038/s41598-01832544-6 
27. Hujoel P. Dietary carbohydrates and dental-systemic diseases. J Dent Res. 2009;88(6):490-502. doi:10.1177/0022034509337700

28. Gondivkar SM, Gadbail AR, Gondivkar RS, et al. Nutrition and oral health. Dis Mon. 2019;65(6):147-154. doi:10.1016/j. disamonth.2018.09.009

29. Mazur M, Bietolini S, Bellardini D, et al. Oral health in a cohort of individuals on a plant-based diet: a pilot study. Clin Ter. 2020;171(2): e142-e148. doi:10.7417/CT.2020.2204

30. Laffranchi L, Zotti F, Bonetti S, et al. Oral implications of the vegan diet: observational study. Minerva Stomatol. 2010;59(1112):583-591.

31. Smits KP, Listl S, Jevdjevic M. Vegetarian diet and its possible influence on dental health: a systematic literature review. Commun Dent Oral Epidemiol. 2020;48(1):7-13. doi:10.1111/cdoe.12498

32. Mummolo S, Mummolo S, Severino M, et al. Periodontal disease in subjects suffering from coronary heart disease. $J$ Biol Regul Homeost Agents. 2019;33(3 Suppl. 1):73-82.

33. Nota A, Abati S, Bosco F, et al. General health, systemic diseases and oral status in adult patients with coeliac disease. Nutrients. 2020;12 (12):3836. doi:10.3390/nu12123836

34. Glickman I. The relation of experimental diabetes to periodontal disease. Am J Orthod. 1947;33(10):703-722. doi:10.1016/00966347(47)90288-3

35. Baumgartner S, Imfeld T, Schicht $\mathrm{O}$, et al. The impact of the stone age diet on gingival conditions in the absence of oral hygiene. J Periodontol. 2009;80(5):759-768. doi:10.1902/jop.2009.080376

36. Woelber JP, Bremer K, Vach K, et al. An oral health optimized diet can reduce gingival and periodontal inflammation in humans-a randomized controlled pilot study. BMC Oral Health. 2017;17(1):1-8. doi:10.1186/s12903-016-0257-1

37. Lula EC, Ribeiro CC, Hugo FN, et al. Added sugars and periodontal disease in young adults: an analysis of NHANES III data. Am J Clin Nutr. 2014;100(4):1182-1187. doi:10.3945/ajcn.114.089656

38. Jenzsch A, Eick S, Rassoul F, et al. Nutritional intervention in patients with periodontal disease: clinical, immunological and microbiological variables during 12 months. Br J Nutr. 2009;101 (6):879-885. doi:10.1017/S0007114508047776

39. Merchant AT, Pitiphat W, Franz M, et al. Whole-grain and fiber intakes and periodontitis risk in men. Am J Clin Nutr. 2006;83 (6):1395-1400. doi:10.1093/ajen/83.6.1395

40. Reeves AF, Rees JM, Schiff M, et al. Total body weight and waist circumference associated with chronic periodontitis among adolescents in the United States. Arch Pediatr Adolesc Med. 2006;160 (9):894-899. doi:10.1001/archpedi.160.9.894

41. Dalla Vecchia CF, Susin C, Rösing CK, et al. Overweight and obesity as risk indicators for periodontitis in adults. $J$ Periodontol. 2005;76 (10):1721-1728. doi:10.1902/jop.2005.76.10.1721

42. Merchant AT, Pitiphat W, Rimm EB, et al. Increased physical activity decreases periodontitis risk in men. Eur J Epidemiol. 2003;18 (9):891-898. doi:10.1023/A:1025622815579

43. Chapple IL, Bouchard P, Cagetti MG, et al. Interaction of lifestyle, behaviour or systemic diseases with dental caries and periodontal diseases: consensus report of group 2 of the joint EFP/ORCA workshop on the boundaries between caries and periodontal diseases. $J$ Clin Periodontol. 2017;44(Suppl 18):S39-S51. doi:10.1111/jcpe.12685

44. Kasprzak A, Kwasniewski W, Adamek A, Gozdzicka-Jozefiak A. Insulin-like growth factor (IGF) axis in cancerogenesis. Mutation Res/Rev Mutation Res. 2017;772:78-104.

45. Allen NE, Appleby PN, Davey GK, Kaaks R, Rinaldi S, Key TJ. The associations of diet with serum insulin-like growth factor I and its main binding proteins in 292 women meat-eaters, vegetarians, and vegans. Cancer Epidemiol Prev Biomark. 2002;11(11):1441-1448.

46. Richter CK, Skulas-Ray AC, Champagne CM, et al. Plant protein and animal proteins: do they differentially affect cardiovascular disease risk? Adv Nutr. 2015;6(6):712-728. doi:10.3945/an.115.009654
47. Staufenbiel I, Weinspach K, Förster G, et al. Periodontal conditions in vegetarians: a clinical study. Eur J Clin Nutr. 2013;67(8):836-840. doi:10.1038/ejen.2013.101

48. Fernández-San Juan P-M. Trans fatty acids (tFA): sources and intake levels, biological effects and content in commercial Spanish food. Nutricion Hospitalaria. 2009;24(5):515-520.

49. Iwasaki M, Manz MC, Moynihan P, et al. Relationship between saturated fatty acids and periodontal disease. J Dent Res. 2011;90 (7):861-867. doi:10.1177/0022034511405384

50. Serhan CN, Chiang N, Dalli J. The resolution code of acute inflammation: novel pro-resolving lipid mediators in resolution. Semin Immunol. 2015;27:200-215. doi:10.1016/j.smim.2015.03.004

51. Elkhouli A. The efficacy of host response modulation therapy (omega-3 plus low-dose aspirin) as an adjunctive treatment of chronic periodontitis (clinical and biochemical study). $J$ Periodontal Res. 2011;46(2):261-268. doi:10.1111/j.16000765.2010.01336.x

52. Raffaelli L, Serini S, Piccioni E, et al. N-3 polyunsaturated fatty acid effect in periodontal disease: state of art and possible mechanisms involved. Int $J$ Immunopathol Pharmacol. 2008;21(2):261-266. doi:10.1177/039463200802100202

53. Mustafa M, Zarrough A, Bolstad AI, et al. Resolvin D1 protects periodontal ligament. Am J Physiol Cell Physiol. 2013;305(6): C673-C679. doi:10.1152/ajpcell.00242.2012

54. Simopoulos AP. Evolutionary aspects of diet, the omega-6/omega-3 ratio and genetic variation: nutritional implications for chronic diseases. Biomed Pharmacother. 2006;60(9):502-507. doi:10.1016/j. biopha.2006.07.080

55. Mantzioris E, James MJ, Gibson RA, et al. Dietary substitution with an $\alpha$-linolenic acid-rich vegetable oil increases eicosapentaenoic acid concentrations in tissues. Am J Clin Nutr. 1994;59(6):1304-1309. doi:10.1093/ajen/59.6.1304

56. Parian AM, Mullin GE. Fish consumption and health: the yin and yang. Nutr Clin Pract. 2016;31(4):562-565. doi:10.1177/ 0884533616651069

57. Van der Velden U, Kuzmanova D, Chapple I. Micronutritional approaches to periodontal therapy. $J$ Clin Periodontol. 2011;38:142-158. doi:10.1111/j.1600-051X.2010.01663.x

58. Freeland-Graves JH, Lin P-H. Plasma uptake of manganese as affected by oral loads of manganese, calcium, milk, phosphorus, copper, and zinc. J Am Coll Nutr. 1991;10(1):38-43. doi:10.1080/ 07315724.1991.10718124

59. Zong G, Holtfreter B, Scott AE, et al. Serum vitamin B12 is inversely associated with periodontal progression and risk of tooth loss: a prospective cohort study. J Clin Periodontol. 2016;43(1):2-9. doi: $10.1111 /$ jcpe. 12483

60. Rizzo G, Laganà A, Rapisarda A, et al. Vitamin B12 among vegetarians: status, assessment and supplementation. Nutrients. 2016;8 (12):767. doi:10.3390/nu8120767

61. Russell A. International nutrition surveys: a summary of preliminary dental findings. $J$ Dent Res. 1963;42(1):233-244. doi:10.1177/ 00220345630420012401

62. Dommisch H, Kuzmanova D, Jönsson D, et al. Effect of micronutrient malnutrition on periodontal disease and periodontal therapy. Periodontol 2000. 2018;78(1):129-153. doi:10.1111/prd.12233

63. Dodington DW, Fritz PC, Sullivan PJ, et al. Higher intakes of fruits and vegetables, beta-carotene, vitamin C, alpha-tocopherol, EPA, and DHA are positively associated with periodontal healing after nonsurgical periodontal therapy in nonsmokers but not in smokers. $J$ Nutr. 2015;145(11):2512-2519. doi:10.3945/jn.115.211524

64. Neiva RF, Al-Shammari K, Nociti FH, et al. Effects of vitamin-B complex supplementation on periodontal wound healing. J Periodontol. 2005;76(7):1084-1091. doi:10.1902/jop.2005.76.7.1084

65. Pack AR. Folate mouthwash: effects on established gingivitis in periodontal patients. J Clin Periodontol. 1984;11(9):619-628. doi:10.1111/j.1600-051X.1984.tb00914.x 
66. Timmerman MF, Abbas F, Loos BG. Java project on periodontal diseases: the relationship between vitamin $\mathrm{C}$ and the severity of periodontitis. J Clin Periodontol. 2007;34(4):299-304. doi:10.1111/ j.1600-051X.2007.01053.x

67. Lee J-H, Shin MS, Kim EJ, Ahn YB, Kim HD. The association of dietary vitamin $\mathrm{C}$ intake with periodontitis among Korean adults: results from KNHANES IV. PLoS One. 2017;12(5):e0177074. doi:10.1371/journal.pone.0177074

68. Staudte H, Sigusch B, Glockmann E. Grapefruit consumption improves vitamin $\mathrm{C}$ status in periodontitis patients. $\mathrm{Br}$ Dent $\mathrm{J}$. 2005;199(4):213-217. doi:10.1038/sj.bdj.4812613

69. Abou Sulaiman AE, Shehadeh RM. Assessment of total antioxidant capacity and the use of vitamin $\mathrm{C}$ in the treatment of non-smokers with chronic periodontitis. J Periodontol. 2010;81(11):1547-1554. doi:10.1902/jop.2010.100173

70. Amaliya A, Laine ML, Delanghe JR, et al. Java project on periodontal diseases: periodontal bone loss in relation to environmental and systemic conditions. J Clin Periodontol. 2015;42(4):325-332. doi: $10.1111 /$ jcpe. 12381

71. Jacob RA, Omaye ST, Skala JH, Leggott PJ, Rothman DL, Murray PA. Experimental vitamin $\mathrm{C}$ depletion and supplementation in young men: nutrient interactions and dental health effects. Ann N Y Acad Sci. 1987;498(1):333-346. doi:10.1111/j.1749-6632.1987. tb23772.x

72. Nakamoto T, McCroskey M, Mallek HM. The role of ascorbic acid deficiency in human gingivitis - a new hypothesis. $J$ Theor Biol. 1984;108(2):163-171. doi:10.1016/S0022-5193(84)80063-6

73. De Carvalho CG, Ribeiro S. Aging, low-grade systemic inflammation and vitamin D: a mini-review. Eur J Clin Nutr. 2017;71(4):434-440. doi:10.1038/ejcn.2016.177

74. Laky M, Bertl K, Haririan H, et al. Serum levels of 25-hydroxyvitamin D are associated with periodontal disease. Clin Oral Investig. 2017;21(5):1553-1558. doi:10.1007/s00784-016-19652

75. Dietrich T, Nunn M, Dawson-Hughes B, Bischoff-Ferrari HA. Association between serum concentrations of 25-hydroxyvitamin $\mathrm{D}$ and gingival inflammation-. Am J Clin Nutr. 2005;82 (3):575-580. doi:10.1093/ajcn/82.3.575

76. Lindblad M, Tveden-Nyborg P, Lykkesfeldt J. Regulation of vitamin C homeostasis during deficiency. Nutrients. 2013;5(8):2860-2879. doi:10.3390/nu5082860

77. Iwasaki M, Moynihan P, Manz MC, et al. Dietary antioxidants and periodontal disease in community-based older Japanese: a 2-year follow-up study. Public Health Nutr. 2013;16(2):330-338. doi:10.1017/S1368980012002637
78. Varela-López A, Giampieri F, Bullón P, et al. A systematic review on the implication of minerals in the onset, severity and treatment of periodontal disease. Molecules. 2016;21(9):1183. doi:10.3390/ molecules21091183

79. Woelber JP, Tennert C. Diet and periodontal diseases. Impact Nutr Diet Oral Health. 2020;28:125-133.

80. Meisel P, Schwahn C, Luedemann J, John U, Kroemer HK, Kocher T. Magnesium deficiency is associated with periodontal disease. $J$ Dent Res. 2005;84(10):937-941. doi:10.1177/154405910508401012

81. Najeeb S, Zafar MS, Khurshid Z, Zohaib S, Almas K. The Role of Nutrition in Periodontal Health: An Update. Nutrients. 2016;30;8 (9):530. doi: 10.3390/nu8090530

82. Nishida M, Grossi SG, Dunford RG, Ho AW, Trevisan M, Genco RJ. Dietary vitamin $\mathrm{C}$ and the risk for periodontal disease. J Periodontol. 2000;71(8):1215-1223. doi:10.1902/jop.2000.71.8.1215

83. Al-Zahrani MS. Increased intake of dairy products is related to lower periodontitis prevalence. J Periodontol. 2006;77(2):289-294. doi:10.1902/jop.2006.050082

84. Adegboye AR, Twetman S, Christensen LB, et al. Intake of dairy calcium and tooth loss among adult Danish men and women. Nutrition. 2012;28(7-8):779-784. doi:10.1016/j.nut.2011.11.011

85. Chapple IL, Milward MR, Ling-Mountford N, et al. Adjunctive daily supplementation with encapsulated fruit, vegetable and berry juice powder concentrates and clinical periodontal outcomes: a doubleblind RCT. J Clin Periodontol. 2012;39(1):62-72. doi:10.1111/ j.1600-051X.2011.01793.X

86. Widén C, Coleman M, Critén S, Karlgren-Andersson P, Renvert S, Persson GR. Consumption of bilberries controls gingival inflammation. Int J Mol Sci. 2015;16(5):10665-10673. doi:10.3390/ ijms160510665

87. Lertpimonchai A, Rattanasiri S, Vallibhakara SA, Attia J, Thakkinstian A. The association between oral hygiene and periodontitis: a systematic review and meta-analysis. Int Dent J. 2017;67 (6):332-343. doi:10.1111/idj.12317

88. Bakdash B. Oral hygiene and compliance as risk factors in periodontitis. J Periodontol. 1994;65:539-544. doi:10.1902/ jop.1994.65.5s.539

89. Zimmermann H, Zimmermann N, Hagenfeld D, Veile A, Kim TS, Becher H. Is frequency of tooth brushing a risk factor for periodontitis? A systematic review and meta-analysis. Community Dent Oral Epidemiol. 2015;43(2):116-127. doi:10.1111/cdoe.12126
Clinical, Cosmetic and Investigational Dentistry

\section{Publish your work in this journal}

Clinical, Cosmetic and Investigational Dentistry is an international, peer-reviewed, open access, online journal focusing on the latest clinical and experimental research in dentistry with specific emphasis on cosmetic interventions. Innovative developments in dental materials, techniques and devices that improve outcomes and patient satisfaction and preference will be highlighted. The manuscript management system is completely online and includes a very quick and fair peer-review system, which is all easy to use. Visit http://www.dovepress.com/testimonials.php to read real quotes from published authors. 